\title{
Avaliação dos componentes da produtividade de grãos em feijão de grãos especiais
}

\author{
Evaluation of grain yield components in special grains bean cultivars
}

\author{
Nerinéia Dalfollo RIBEIRO ${ }^{1}$; Lucas da Silva DOMINGUES ${ }^{2}$; Allan Emanoel Mezzomo ZEMOLIN³ \\ ${ }^{1}$ Autor para correspondência. Professor Associado II, Universidade Federal de Santa Maria (UFSM), Centro de \\ Ciências Rurais, Departamento de Fitotecnia. Av. Roraima, n.1000. CEP 97105- 900. Campus Santa Maria, \\ Santa Maria, RS. Fone/fax: (55) 3220-8899, ramal 229.nerineia@hotmail.com e nerineia.ribeiro@gmail.com \\ ${ }^{2}$ Professor Adjunto I, Universidade Tecnológica Federal do Paraná, Curso de Agronomia, Campus Dois Vizinhos. \\ Estrada Boa Esperança, Km 04, Cx P. 157, CEP 85660-000. Dois Vizinhos, PR. \\ lucassdomingues@hotmail.com \\ ${ }^{3}$ Aluno do Programa de Pós-graduação em Agronomia (PPGA), UFSM. 97105- 900. Santa Maria, RS. Bolsista \\ de mestrado da CAPES. E-mail: allan_zemolin@hotmail.com
}

Recebido em: 01-07-2013; Aceito em: 05-03-2014

\begin{abstract}
Resumo
O melhoramento de feijão de grãos especiais ainda é restrito no Brasil. Portanto, foram objetivos deste trabalho avaliar os efeitos da interação linhagem $x$ ambiente sobre os componentes da produtividade de grãos em feijão de grãos especiais, selecionar linhagens de alta produtividade de grãos e avaliar a associação linear e as relações diretas e indiretas entre os componentes da produtividade de grãos. Para tanto, 29 linhagens de feijão de grãos especiais foram avaliadas em diferentes locais, anos e épocas de cultivo. Interação linhagem $x$ ambiente significativa foi obtida para o número de vagens por planta, o número de grãos por planta, o número de grãos por vagem, a massa de 100 grãos e a produtividade de grãos. As cultivares IAC Galante, Xamego, BRS MG Realce e Rosinha G2 apresentaram alta produtividade de grãos, sendo seu cultivo promissor para os ambientes avaliados. Coeficiente de correlação linear positivo foi obtido entre a produtividade de grãos e o número de vagens por planta $(r=0,4704)$ e o número de grãos por vagem $(r=0,4254)$. Esses caracteres também apresentaram os maiores efeitos diretos sobre a produtividade de grãos. A seleção indireta para o número de vagens por planta e o número de grãos por vagem é de eficiência moderada para o aumento da produtividade de grãos, em linhagens de feijão de grãos especiais.
\end{abstract}

Palavras-chave adicionais: análise de trilha; correlação de Pearson; interação genótipo $x$ ambiente; linhas puras; Phaseolus vulgaris L..

\begin{abstract}
The genetic improvement of special grains bean cultivars is still very limited in Brazil. The objective of this study was to evaluate the effects of the interaction line $x$ environment on grain yield components in special grains bean cultivars, select high grain yield lines and to evaluate the linear association and the direct and indirect relations between the grain yield components. So, 29 special grains bean lines were studied in several places, years and cultivation time. Significant interaction line $x$ environment was observed for number of pods per plant, number of grains per plant number of grains per pod, the mass of 100 grains and grain yield. Cultivars 'IAC Galante', 'Xamego', 'BRS MG Realce', and 'Rosinha' showed high grain yield and are thus indicated for cultivation under the studied conditions. A positive linear correlation coefficient was observed between grain yield and number of pods per plant $(r=0.4704)$ and the number of grains per pod $(r=0.4254)$. These characters had also the highest direct effects on grain yield. The indirect selection for number of pods per plant and the number of grains per pod is of moderate efficiency for grain yield increments.
\end{abstract}

Additional keywords: inbred lines; interaction genotype $x$ environment; path analysis; Pearson correlations; Phaseolus vulgaris L.. 


\section{Introdução}

O feijão (Phaseolus vulgaris L.) representa $50 \%$ do volume de grãos consumidos no mundo (TALUKDER et al., 2010) e é a principal fonte de proteína usada na alimentação humana em vários países da América Latina e da África Oriental e do Sul (BROUGHTON et al., 2003). O Brasil é o maior produtor e consumidor mundial de feijão, com uma área cultivada de 3,67 milhões de hectares e uma produção de 3,137 milhões de toneladas (CONAB, 2012).

No Brasil, predomina o cultivo de feijão de grãos Mesoamericanos que apresentam massa de 100 grãos inferior a $25 \mathrm{~g}$ (BLAIR et al., 2010). Os grãos carioca e preto correspondem a 70\% e a $15 \%$ da produção nacional, respectivamente (CTSBF, 2010). Por isso, os programas de melhoramento têm registrado e protegido maior número de cultivares de feijão destas classes de grãos no Ministério da Agricultura, Pecuária e Abastecimento (MAPA, 2012).

Os grãos Andinos possuem massa de 100

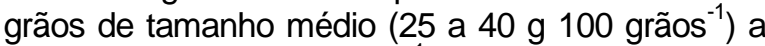

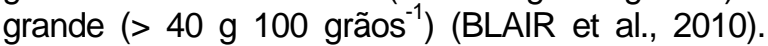
Nesse grupo, encontram-se cultivares de tegumento branco, vermelho, creme, amarelo e de outras cores - com ausência ou presença de estrias ou rajas de outras cores, conhecidos como feijão de grãos especiais. Esses grãos têm grande aceitação no mercado internacional (THUNG et al., 2009), mas a produção no Brasil ainda é muito restrita.

No Estado do Rio Grande do Sul (RS), há apenas uma cultivar de feijão de grãos especiais registrada para o cultivo, a Iraí (MAPA, 2012). Esta cultivar apresenta grãos rajados (fundo bege com rajas vermelhas), hábito de crescimento determinado (tipo I), ciclo precoce e alta instabilidade de produção quando cultivada no RS (PIANA et al., 1999). Por isso, a identificação de novas cultivares de feijão de grãos especiais com alta produtividade de grãos representa vantagens mercadológicas para os produtores de feijão.

Entretanto, para que o processo de desenvolvimento de novas cultivares de feijão de grãos especiais seja mais eficiente, é preciso conhecer com maior profundidade as correlações entre os caracteres de produção. Em feijão de grãos Mesoamericanos, foi possível constatar que a produtividade de grãos apresentou correlação positiva e de alta magnitude com o número de vagens por planta (FURTADO et al., 2002), o número de grãos por planta (RIBEIRO et al., 2001a; RIBEIRO et al., 2001b) e a massa de 100 grãos (KUREK et al., 2001).

A magnitude dessas correlações varia com a diversidade genética do germoplasma avaliado (KUREK et al., 2001; RIBEIRO et al., 2001a; RIBEIRO et al., 2001b; FURTADO et al., 2002; CABRAL et al., 2011), com os anos (RIBEIRO et al., 2003) e com os locais de avaliação (BARILI et al., 2011; ZILIO et al., 2011). Por isso, são encontrados resultados distintos na literatura para a análise de correlação linear simples e para a análise de trilha em feijão. Para minimizar esse problema, Cargnelutti Filho et al. (2011) recomendaram o uso de sete experimentos para a análise de trilha dos componentes da produtividade de grãos em feijão. Entretanto, nem sempre é possível conduzir um número tão elevado de experimentos para se fazer inferências sobre a análise de trilha em feijão.

Considerando que os componentes da produtividade de grãos em feijão são afetados pela interação linhagem $x$ ambiente (ZILIO et al., 2011), a avaliação em diferentes ambientes de cultivo fazse necessária. Isto porque haverá um caráter com maior efeito direto sobre a produtividade de grãos em cada ambiente, dificultando a execução da seleção indireta. Por isso, a realização da análise de trilha com os dados médios obtidos em anos, épocas e locais de cultivo parece ser a melhor alternativa para o programa de melhoramento.

Para feijão de origem Andina, não foram encontrados trabalhos de investigação da associação linear e as relações diretas e indiretas entre os componentes da produtividade de grãos. Portanto, foram objetivos deste trabalho avaliar os efeitos da interação linhagem $x$ ambiente sobre os componentes da produtividade de grãos em feijão de grãos especiais, selecionar linhagens de alta produtividade de grãos e avaliar a associação linear $e$ as relações diretas $e$ indiretas entre os componentes da produtividade de grãos.

\section{Material e métodos}

Os experimentos de campo foram instalados em área do Departamento de Fitotecnia da Universidade Federal de Santa Maria (UFSM), Campus de Santa Maria, Rio Grande do Sul - RS (latitude $29^{\circ} 42^{\prime} \mathrm{S}$, longitude $53^{\circ} 49^{\prime} \mathrm{W}$ e $95 \mathrm{~m}$ de altitude) e no Instituto Federal Farroupilha (IFF), Campus de Jaguari-RS (latitude $29^{\circ} 27^{\prime}$ S, longitude $54^{\circ} 43^{\prime} \mathrm{W}$ e altitude de $395 \mathrm{~m}$ ). Na UFSM, foram realizados os cultivos de safra agrícola (2010/2011 e 2011/2012) e de safrinha (2011) e no IFF, o cultivo de safra agrícola 2011/2012. A semeadura foi realizada no mês de outubro, na safra agrícola, e no mês de fevereiro na safrinha.

O delineamento experimental utilizado foi o de blocos casualizados, com três repetições. As parcelas foram constituídas por duas linhas de $4 \mathrm{~m}$ de comprimento, espaçadas em $0,5 \mathrm{~m}$, e área útil de $4 \mathrm{~m}^{2}$. Os tratamentos consistiram na avaliação de 29 linhagens de feijão de grãos especiais. No cultivo de safra 2010/2011, foram avaliadas 11 linhagens (Light Red Kidney, Red Kanner, Ouro Branco, Montcalm, IPR Garça, Chinook, Hooter, BRS Radiante, Cal 96, Branco Graúdo e WAF 75), sendo essas as linhagens comuns nos quatro ambientes. As linhagens avaliadas apresentam 
diferenças quanto à coloração de tegumento, sendo quatro de grãos brancos: WAF 75, Ouro Branco, Branco Graúdo e IPR Garça; onze de grãos rajados: Hooter, BRS Radiante, Cal 96, IAC Harmonia, OTG 07-01, OTG 07-03, IAC Boreal, BRS MG Realce, Cranberry, OTG 07-09 e Iraí; oito de grãos vermelhos: Light Red Kidney, Red Kanner, Montcalm, Chinook, TB 02-24, Vermelho Graúdo, Xamego e Dark Red Kidney; dois de grãos verdes: IAC Jabola e IAC Esperança; dois de grãos rosas: IAC Galante e Rosinha G2; um de grãos bege: IAC Centauro; e um de grãos mouros (cor de fundo cinza com listras pretas): 39 MON p5-13. Como foram avaliadas cultivares crioulas, cultivares comerciais e linhagens avançadas de diferentes obtentores, optou-se pela denominação de linhagens, pois todos os acessos apresentam alta homozigose.

Em Santa Maria, o solo foi preparado de maneira convencional. A correção da acidez do solo e a adubação foram realizadas de acordo com a interpretação da análise química do solo. As plantas invasoras foram controladas mecanicamente, e o controle de insetos foi executado com a aplicação do inseticida Metamidofós Fersol 600 (Metamidofós $600 \mathrm{~g} \mathrm{~L}^{-1}$ ), sempre que necessário, a fim de não comprometer o desenvolvimento da cultura. O controle de doenças não foi efetuado. A irrigação por aspersão foi realizada para garantir 0 estabelecimento da cultura e o enchimento de grãos.

Em Jaguari, adotou-se o cultivo mínimo do solo, e o controle de plantas invasoras foi efetuado com a aplicação dos herbicidas Robust (Fluazifopep-butilico $200 \mathrm{~g} \mathrm{~L}^{-1}$ e Fomesafen $250 \mathrm{~g} \mathrm{~L}^{-1}$ ) e Basagran (Bentazona $600 \mathrm{~g} \mathrm{~L}^{-1}$ ). A irrigação foi realizada por pivô central, e as demais práticas de manejo foram similares àquelas descritas para Santa Maria.

Os componentes da produtividade de grãos - número de vagens por planta, número de grãos por planta, número de grãos por vagem e massa de 100 grãos, foram determinados na maturação. Com exceção da massa de 100 grãos, os componentes da produtividade de grãos foram avaliados em 10 plantas colhidas ao acaso na área útil. As demais plantas da parcela útil foram colhidas manualmente na maturação e trilhadas sem 0 uso de máquinas e de equipamentos agrícolas. Após a remoção manual das impurezas e dos grãos quebrados, os grãos obtidos foram secos em estufa de secagem e de esterilização com circulação forçada (65 a 70ํㅡ), até umidade média de $13 \%$, quando se determinaram a massa de 100 grãos e a produtividade de grãos $\left(\mathrm{kg} \mathrm{ha}^{-1}\right)$.

Os dados obtidos foram submetidos à análise de variância individual e conjunta, segundo o modelo de blocos casualizados, exceto para a massa de 100 grãos, que foi analisada de acordo com o delineamento inteiramente casualizado, pois não se utilizaram as mesmas repetições do campo. A massa de 100 grãos foi determinada em três subamostras de 100 grãos, coletadas de forma aleatória nos grãos obtidos na repetição 1. Na análise de variância conjunta, a interação foi estimada para as linhagens comuns, nos quatro ambientes, e para a comparação das médias, foram usados o quadrado médio e o grau de liberdade da análise conjunta. $O$ teste de Bartlett (STEEL et al., 1997) foi aplicado para verificar a homogeneidade das variâncias dos erros entre os ambientes de cultivo. O teste $F$ (valor de $p<0,05)$ foi usado para os testes das hipóteses dos efeitos principais e da interação linhagem $x$ ambiente. $O$ efeito de linhagem foi considerado fixo, e os demais (bloco, ambientes e interação), aleatórios. O teste Scott-Knott foi usado para comparar as médias entre as linhagens, dentro de um mesmo ambiente, e o teste de Tukey, para comparar as médias entre os ambientes, para cada linhagem. Ambos os testes de comparação de médias foram efetuados adotando-se o nível de significância de $5 \%$ de probabilidade (valor de $p=0,05$ ).

Com os dados médios dos quatro ambientes, foi estimada a matriz com os coeficientes de correlação linear de Pearson entre os cinco caracteres e verificou-se a significância dos coeficientes por meio do teste $t$ de Student (valor de $p=0,05)$. O diagnóstico de multicolinearidade foi realizado conforme critério de Montgomery \& Peck (1982), descrito em Cruz \& Carneiro (2003), visando a eliminar caracteres que possam resultar em coeficientes viesados na análise de trilha. Após, foi realizada a análise de trilha da produtividade de grãos em função dos demais caracteres, que são explicativos. As análises foram realizadas com 0 auxílio da planilha eletrônica Office Excel e do programa Genes (CRUZ, 2006).

\section{Resultados e discussão}

A variância do erro experimental dos ambientes de cultivo foi homogênea (valor-p >0,05), possibilitando a realização da análise de variância conjunta para todos os caracteres avaliados. $\mathrm{Na}$ análise de variância conjunta, observaram-se efeitos significativos para linhagens, ambientes e interação linhagem $x$ ambiente (valor de $p<0,05$ ) para todos os caracteres de produção (Tabela 1). Portanto, houve resposta diferenciada das linhagens de feijão de grãos especiais para todos os caracteres avaliados, pois as condições edafoclimáticas não foram constantes nos anos agrícolas, épocas de semeadura e locais de cultivo. Interação linhagem $x$ ambiente significativa foi descrita previamente para 0 número de vagens por planta e o número de grãos por vagem em feijão crioulo (ZILIO et al., 2011) e para a produtividade de grãos em feijão de grãos especiais (MELO et al., 2007; FARIA et al., 2009; GONÇALVES et al., 2010). 
Tabela 1 - Análise de variância conjunta dos dados de número de vagens por planta (NVP), número de grãos por planta (NGP), número de grãos por vagem (NGV), massa de 100 grãos (M100G, g) e produtividade de grãos (PROD, $\mathrm{kg} \mathrm{ha}^{-1}$ ) de linhagens de feijão de grãos especiais obtidas em quatro ambientes.

\begin{tabular}{|c|c|c|c|c|}
\hline \multirow{2}{*}{ Fonte de variação } & \multirow{2}{*}{$\mathrm{GL}$} & \multicolumn{3}{|c|}{ Quadrado médio do erro ${ }^{1}$} \\
\hline & & NVP & NGP & NGV \\
\hline Linhagens (L) & 28 & $55,82^{*}$ & $1306,88^{*}$ & $2,19^{*}$ \\
\hline Ambientes $(A)$ & 3 & $124,11^{*}$ & $1655,68^{*}$ & $1,00^{*}$ \\
\hline$L \times A$ & 66 & $17,51^{\star}$ & $257,72^{*}$ & $0,11^{*}$ \\
\hline Bloco/E & 8 & $5,39^{\text {ns }}$ & $81,77^{\mathrm{ns}}$ & $0,06^{\mathrm{ns}}$ \\
\hline Erro & 188 & 7,58 & 132,19 & 0,08 \\
\hline Média & & 9,81 & 30,82 & 3,07 \\
\hline CV \% & & 28,07 & $-37,3$ & 9,25 \\
\hline & GL & M100G & GL. & PROD \\
\hline Linhagens (L) & 28 & $721,97^{*}$ & 28 & $8 \overline{1} \overline{1} \overline{110}, \overline{6} \overline{7}^{*}$ \\
\hline Ambientes $(A)$ & 3 & $168,05^{*}$ & 3 & $6186134,35^{*}$ \\
\hline$L \times A$ & 66 & $29,72^{*}$ & 66 & $233044,01^{\star}$ \\
\hline Bloco/E & -- & -- & 8 & $95918,03^{\text {ns }}$ \\
\hline Erro & 196 & 7,50 & 188 & 93727,82 \\
\hline Média & & 41,18 & & 1207,69 \\
\hline $\mathrm{CV} \%^{2}$ & & 6,65 & & 25,35 \\
\hline
\end{tabular}

* Significativo pelo teste $F(\mathrm{p}=0,05) ; \mathrm{ns}=$ não significativo; ${ }^{2} \mathrm{CV} \%$ : coeficiente de variação.

No cultivo de safra de 2010/2011 em Santa Maria, a linhagem Branco Graúdo apresentou o maior número de vagens por planta $(23,7)$ (Tabela 2). Já, na safrinha de 2011 em Santa Maria, destacaram-se as linhagens IAC Galante $(14,9)$ e IAC Centauro $(14,5)$, e na safra de 2011/2012, em Jaguari, as linhagens Chinook $(16,6)$, IAC Galante $(16,9)$ e Xamego $(18,3)$. No cultivo de safra de 2011/2012, em Santa Maria, 15 linhagens apresentaram maior número de vagens por planta, com valores variando de 9,1 a 13,3. Zilio et al. (2011), também, observaram ampla variação para o número de vagens por planta avaliado em 26 cultivares crioulas de feijão cultivadas em três municípios de Santa Catarina.

O número de grãos por vagem variou de 2,2 (Chinook, no cultivo de safra de 2011/2012, em Jaguari) a 6,7 (IAC Centauro, no cultivo de safra de 2011/2012, em Jaguari) (Tabela 2). Esses valores são considerados baixos, pois todas as linhagens avaliadas são da espécie Phaseolus vulgaris L., que se caracteriza por apresentar de quatro a dez grãos por vagem (ZIMMERMANN \& TEIXEIRA, 1996). A ocorrência de alta temperatura do ar no período reprodutivo, nos diferentes ambientes de cultivo, provavelmente, contribuiu para a menor fixação do número de grãos por vagem, em muitas linhagens avaliadas no presente estudo. Isso porque o feijão é muito sensível à temperatura do ar no período de floração. Gonçalves et al. (1997) observaram que, quando a temperatura superou os $30{ }^{\circ} \mathrm{C}$, na floração das plantas de feijão, houve redução do número de vagens por planta, do número de grãos por vagem e da produtividade de grãos.

A massa de 100 grãos apresentou amplitude de 20,8 (Xamego, no cultivo de safrinha de 2011 em Santa Maria) a 55,6 g (WAF 75, no cultivo de safrinha de 2011 em Santa Maria) (Tabela 3). De acordo com a classificação de tamanho de grãos apresentada por Blair et al. (2010), apenas duas linhagens: Xamego e Rosinha G2, pertencem ao grupo gênico Mesoamericano, pois a massa de 100 grãos foi inferior a $25 \mathrm{~g} 100$ grãos $^{-1}$. As demais linhagens avaliadas são do grupo gênico Andino, e de acordo com a massa média de 100 grãos, apresentaram grãos de tamanho médio (25 a $40 \mathrm{~g} 100$ grãos $^{-1}$ ): BRS Radiante, IAC Galante, IAC Centauro, BRS MG Realce, Iraí, TB 02-24, 38 MOM p5-13 e IAC Esperança; e grande ( $>40 \mathrm{~g} 100$ grãos $\left.^{-1}\right)$ : Ligth Red Kidney, Red Kanner, Ouro Branco, Montcalm, IPR Garça, Chinook, Hooter, Cal 96, Branco Graúdo, WAF 75, Vermelho Graúdo, IAC Harmonia, Dark Red Kidney, IAC Jabola, Cranberry, OTG 07-09, IAC Boreal, OTG 07-03 e OTG 07-01. A identificação de linhagens de feijão de grãos especiais de tamanho grande e com tegumentos branco, vermelho e rajado representa vantagens mercadológicas aos produtores de feijão, pois de acordo com Thung et al. (2009) essas classes de grãos apresentam alto valor comercial e grande demanda no mercado internacional. 
Tabela 2 - Média* do número de vagens por planta (NVP) e do número de grãos por vagem (NGV) de linhagens de feijão de grãos especiais, obtidas em quatro ambientes.

\begin{tabular}{|c|c|c|c|c|c|c|c|c|}
\hline \multirow{2}{*}{ Linhagens } & \multicolumn{4}{|c|}{ NVP } & \multicolumn{4}{|c|}{ NGV } \\
\hline & Amb. $1^{1}$ & Amb. 2 & Amb. 3 & Amb. 4 & Amb. $1^{1}$ & Amb. 2 & Amb. 3 & Amb. 4 \\
\hline Ligth Red Kidney & $9,2 \mathrm{bA}$ & $9,3 c \mathrm{~A}$ & $9,8 \mathrm{aA}$ & $8,7 \mathrm{eA}$ & $3,7 \mathrm{aA}$ & $3,0 \mathrm{cAB}$ & $2,9 \mathrm{cB}$ & $3,6 a A$ \\
\hline Red Kanner & $7,5 \mathrm{bA}$ & $7,8 \mathrm{cA}$ & $9,1 \mathrm{aA}$ & $10,8 d A$ & $3,5 \mathrm{a} A \mathrm{~B}$ & $3,6 \mathrm{bA}$ & $3,2 \mathrm{~b} \mathrm{AB}$ & $3,0 \mathrm{aB}$ \\
\hline Ouro Branco & $10,9 \mathrm{bA}$ & $10,9 \mathrm{bA}$ & $9,6 a A$ & $7,4 \mathrm{eA}$ & $3,2 \mathrm{bA}$ & $2,9 d A$ & $2,7 \mathrm{cA}$ & $2,6 a \mathrm{~A}$ \\
\hline Montcalm & $9,4 \mathrm{bA}$ & $7,2 \mathrm{cA}$ & $8,8 \mathrm{bA}$ & $8,1 \mathrm{eA}$ & $3,4 \mathrm{aA}$ & $2,8 \mathrm{~d} A \mathrm{~B}$ & $2,3 \mathrm{~dB}$ & $2,9 a \mathrm{~A}$ \\
\hline IPR Garça & $10,5 \mathrm{bA}$ & $11,1 \mathrm{bA}$ & $10,0 a A$ & $15,9 \mathrm{bA}$ & $3,0 \mathrm{bA}$ & $2,9 \mathrm{dA}$ & $2,4 \mathrm{dAB}$ & $2,3 \mathrm{aB}$ \\
\hline Chinook & $12,6 b$ AB & $8,5 \mathrm{cB}$ & $9,4 a B$ & 16,6 aA & $3,1 \mathrm{bA}$ & $2,8 \mathrm{dA}$ & $2,5 \mathrm{~d} A \mathrm{~B}$ & $2,2 \mathrm{aB}$ \\
\hline Hooter & $9,5 \mathrm{bA}$ & $9,2 \mathrm{cA}$ & $9,3 a A$ & $10,1 \mathrm{dA}$ & $2,8 \mathrm{~b} \mathrm{~A}$ & $2,6 \mathrm{dA}$ & $2,8 c A$ & $2,9 a \mathrm{~A}$ \\
\hline BRS Radiante & $12,2 \mathrm{bA}$ & $8,2 \mathrm{cA}$ & $8,6 \mathrm{bA}$ & $11,3 d A$ & $3,6 \mathrm{aA}$ & $3,2 \mathrm{cA}$ & $2,9 \mathrm{cA}$ & $3,0 \mathrm{aA}$ \\
\hline Cal 96 & $12,8 \mathrm{~b} A \mathrm{~B}$ & $8,7 \mathrm{cB}$ & $8,6 \mathrm{bB}$ & $15,6 \mathrm{bA}$ & $2,8 \mathrm{~b} \mathrm{~A}$ & $2,9 \mathrm{~d} A$ & $2,4 \mathrm{dA}$ & $2,4 a \mathrm{~A}$ \\
\hline Branco Graúdo & 23,7 a A & $9,7 \mathrm{cA}$ & $11,1 \mathrm{aA}$ & $11,9 \mathrm{dA}$ & $3,0 \mathrm{bA}$ & $2,8 \mathrm{dA}$ & $2,6 c \mathrm{~A}$ & $2,3 a \mathrm{~A}$ \\
\hline WAF 75 & $14,6 \mathrm{bA}$ & $9,3 \mathrm{cA}$ & $7,1 \mathrm{bA}$ & $7,1 \mathrm{eA}$ & $3,2 \mathrm{~b} \mathrm{~A}$ & $2,8 \mathrm{dAB}$ & $2,3 \mathrm{~dB}$ & $3,3 a \mathrm{~A}$ \\
\hline IAC Galante & & $14,9 a \mathrm{~A}$ & $11,9 a A$ & $16,9 a A$ & & $3,4 \mathrm{~b} \mathrm{AB}$ & $3,6 \mathrm{~b} \mathrm{~A}$ & $3,0 \mathrm{aB}$ \\
\hline IAC Centauro & & $14,5 a A$ & $10,1 \mathrm{aA}$ & $15,2 \mathrm{bA}$ & & $4,1 \mathrm{aC}$ & $3,4 \mathrm{bD}$ & 6,7 a A \\
\hline Xamego & & $8,1 \mathrm{cB}$ & $13,3 a A B$ & $18,3 a A$ & & $4,2 \mathrm{aA}$ & $4,4 a \mathrm{~A}$ & $4,2 \mathrm{aA}$ \\
\hline BRS MG Realce & & $7,2 \mathrm{cA}$ & $10,1 \mathrm{aA}$ & $8,8 \mathrm{eA}$ & & $3,2 \mathrm{cA}$ & $2,6 \mathrm{cB}$ & $3,3 a \mathrm{~A}$ \\
\hline Rosinha G2 & & $10,1 \mathrm{cA}$ & $11,2 \mathrm{aA}$ & $15,1 \mathrm{bA}$ & & $3,5 \mathrm{bB}$ & $4,2 \mathrm{aB}$ & 5,1 a A \\
\hline Vermelho & & & & & & & & \\
\hline Graúdo & & $7,2 \mathrm{cA}$ & $4,3 c A$ & $5,6 \mathrm{f} A$ & & $4,4 a \mathrm{~A}$ & $2,8 \mathrm{cB}$ & $2,7 a B$ \\
\hline Iraí & & $11,1 \mathrm{bA}$ & $8,2 \mathrm{bA}$ & $11,6 \mathrm{dA}$ & & $3,5 \mathrm{bA}$ & $2,8 \mathrm{cA}$ & $3,2 \mathrm{aA}$ \\
\hline IAC Harmonia & & $8,3 c \mathrm{~A}$ & $10,5 a A$ & $10,4 d A$ & & $3,1 \mathrm{cA}$ & $3,2 \mathrm{~b} \mathrm{~A}$ & $3,2 \mathrm{aA}$ \\
\hline Dark Red Kidney & & $8,4 \mathrm{cA}$ & $8,7 \mathrm{bA}$ & $8,8 \mathrm{eA}$ & & $3,2 \mathrm{cA}$ & $2,4 \mathrm{dA}$ & $2,7 a \mathrm{~A}$ \\
\hline IAC Jabola & & $7,7 \mathrm{cA}$ & $6,7 \mathrm{cA}$ & $5,4 f A$ & & $2,6 \mathrm{dBC}$ & $2,9 \subset \mathrm{C}$ & $4,4 a \mathrm{~A}$ \\
\hline Cranberry & & $6,5 \mathrm{cA}$ & $7,8 \mathrm{bA}$ & $8,2 \mathrm{eA}$ & & $3,2 \mathrm{cA}$ & $3,2 \mathrm{bA}$ & $3,2 \mathrm{aA}$ \\
\hline OTG 07-09 & & $7,7 \mathrm{cA}$ & $7,7 \mathrm{bA}$ & $8,9 \mathrm{eA}$ & & $3,1 \mathrm{cA}$ & $2,6 \mathrm{dAB}$ & $2,0 \mathrm{aB}$ \\
\hline TB 02-24 & & $9,3 \mathrm{cA}$ & $11,2 a A$ & $10,8 d A$ & & $2,7 d A$ & $3,2 \mathrm{~b} \mathrm{~A}$ & $3,2 a A$ \\
\hline IAC Boreal & & $7,3 \mathrm{cA}$ & $5,0 \mathrm{cA}$ & $9,5 \mathrm{dA}$ & & $2,9 \mathrm{dA}$ & $2,9 \mathrm{cA}$ & $2,4 \mathrm{aA}$ \\
\hline 38 MOM p5-13 & & $6,0 \mathrm{cB}$ & $9,9 a A B$ & $12,5 \mathrm{cA}$ & & $3,0 \mathrm{cB}$ & $3,6 \mathrm{bA}$ & $3,4 \mathrm{a} A \mathrm{~B}$ \\
\hline IAC Esperança & & $9,8 \mathrm{cA}$ & $6,2 c A$ & $4,4 \mathrm{fA}$ & & $3,5 \mathrm{~b} A B$ & $3,2 \mathrm{bB}$ & $4,0 a \mathrm{~A}$ \\
\hline OTG 07-03 & & $6,6 \mathrm{cA}$ & $7,5 \mathrm{bA}$ & $8,4 \mathrm{eA}$ & & $2,6 \mathrm{dA}$ & $2,6 \mathrm{cA}$ & $2,6 a \mathrm{~A}$ \\
\hline OTG 07-01 & & $7,7 \mathrm{cA}$ & $8,3 \mathrm{bA}$ & $7,7 \mathrm{eA}$ & & $2,5 \mathrm{dA}$ & $2,3 \mathrm{dA}$ & $2,4 \mathrm{aA}$ \\
\hline Média & 12,1 & 8,9 & 9,0 & 10,7 & 3,2 & 3,2 & 2,9 & 3,2 \\
\hline C.V. (\%) & 24,3 & 21,5 & 18,4 & 11,7 & 8,9 & 7,5 & 9,5 & 10,5 \\
\hline
\end{tabular}

Médias não seguidas pela mesma letra minúscula na coluna diferem entre si, pelo teste de Scott-Knott $(p=0,05)$, e maiúscula na linha, pelo teste de Tukey ( $p=0,05) ;{ }^{1}$ Ambientes: Amb. 1: cultivo de safra de 2010/2011 em Santa Maria; Amb. 2: cultivo de safrinha em Santa Maria; Amb. 3: cultivo de safra de 2011/2012 em Santa Maria; Amb.4: cultivo de safra de 2011/2012 em Jaguari.

A produtividade de grãos variou entre as linhagens de feijão de grãos especiais, em cada ambiente de cultivo. No cultivo de safra de 2010/2011 em Santa Maria, foram avaliadas apenas 11 linhagens de grãos especiais. Nesta condição, as linhagens Light Red Kidney (1.967 $\mathrm{kg} \mathrm{ha}^{-1}$ ), Red Kanner (1.834 kg ha ${ }^{-1}$ ) e Ouro Branco $\left(1.718 \mathrm{~kg} \mathrm{ha}^{-1}\right.$ ) apresentaram os maiores valores de produtividade de grãos (Tabela 3). Já, na safrinha de 2011 em Santa Maria, destacaram-se as linhagens BRS Radiante, Cal 96, Branco Graúdo, IAC Galante, IAC Centauro, Xamego, BRS MG Realce, Rosinha G2 e Vermelho Graúdo com os valores mais altos de produtividade de grãos (1.333 a $1.717 \mathrm{~kg} \mathrm{ha}^{-1}$ ). $\mathrm{Na}$ safra de 2011/2012, as maiores produtividades de grãos foram obtidas pelas linhagens BRS Radiante, IAC Galante, Xamego, BRS MG Realce, Rosinha G2, Iraí, Cranberry, TB 02-24 e 38 MOM p5-13 em Santa Maria, e pelas linhagens IAC Centauro, Xamego, Rosinha G2, TB 02-24, IAC Boreal e 38 MOM p5-13 em Jaguari.
As cultivares IAC Galante, Xamego, BRS MG Realce e Rosinha G2 apresentaram produtividade de grãos semelhante ou superior à observada na cultivar Iraí (Tabela 3). Portanto, a extensão do registro destas cultivares para o RS poderá ser considerada pelos obtentores. A identificação de novas cultivares de feijão de grãos especiais com alta produtividade de grãos para uso na agricultura familiar é de grande importância para a diversificação da produção de feijão no RS, que atualmente apresenta apenas a cultivar Iraí registrada no MAPA (2012). Nesse cenário, O cultivo das cultivares IAC Galante, Xamego, BRS MG Realce e Rosinha G2 é promissor para os produtores de feijão nos ambientes avaliados. Além disso, o uso destas cultivares em cruzamentos controlados será avaliado pelo programa de melhoramento para o desenvolvimento de novas cultivares de feijão, com cores de tegumento variado e de alta produtividade de grãos. 
Tabela 3 - Média* da massa de 100 grãos (M100G, g) e da produtividade de grãos (PROD., kg ha ${ }^{-1}$ ) de linhagens de feijão de grãos especiais obtidas em quatro ambientes.

\begin{tabular}{|c|c|c|c|c|c|c|c|c|}
\hline \multirow{2}{*}{ Linhagens } & \multicolumn{4}{|c|}{ M100G } & \multicolumn{4}{|c|}{ PROD } \\
\hline & Amb. $1^{1}$ & Amb. 2 & Amb. 3 & Amb. 4 & Amb. $1^{1}$ & Amb. 2 & Amb. 3 & Amb. 4 \\
\hline Ligth Red Kidney & $49,1 \mathrm{a} A$ & $51,5 b \mathrm{~b}$ & $50,4 a \mathrm{~A}$ & $53,5 a \mathrm{~A}$ & 1967a A & $1086 \mathrm{~b} \mathrm{~A}$ & 1177b A & $1658 b \mathrm{~A}$ \\
\hline Red Kanner & $38,4 \mathrm{c} \mathrm{B}$ & $43,5 \mathrm{~d} B$ & $44,1 \mathrm{~b} \mathrm{AB}$ & $49,4 a \mathrm{~A}$ & $1834 a \mathrm{~A}$ & $1224 \mathrm{~b} \mathrm{~A}$ & $1056 \mathrm{~b} \mathrm{~A}$ & $1284 \mathrm{c} \mathrm{A}$ \\
\hline Ouro Branco & $37,1 \mathrm{c} \mathrm{C}$ & $52,8 a \mathrm{~A}$ & $46,8 \mathrm{a} B$ & $52,7 a A$ & $1718 \mathrm{a} A$ & $668 \mathrm{~d} B$ & 1093b A & $1231 \mathrm{c} \mathrm{A}$ \\
\hline Montcalm & $39,3 \mathrm{c} \mathrm{B}$ & $48,5 \mathrm{~b} \mathrm{~A}$ & $45,7 \mathrm{~b} \mathrm{~A}$ & $42,8 \mathrm{~b} \mathrm{~A}$ & $1636 \mathrm{~b} \mathrm{~A}$ & $1124 \mathrm{~b} \mathrm{~A}$ & $742 \mathrm{c} \mathrm{A}$ & $1306 \mathrm{c} \mathrm{A}$ \\
\hline IPR Garça & $37,9 \mathrm{c} \mathrm{B}$ & $41,6 \mathrm{~d} A$ & $44,8 \mathrm{~b} \mathrm{~A}$ & $44,7 \mathrm{~b} \mathrm{~A}$ & $1582 \mathrm{~b} A$ & $436 \mathrm{~dB}$ & $876 b$ AB & $1405 \mathrm{c} \mathrm{A}$ \\
\hline Chinook & $40,8 \mathrm{bB}$ & $46,1 \mathrm{c} A \mathrm{~B}$ & $44,7 \mathrm{~b} B$ & $51,8 \mathrm{a} A$ & $1451 \mathrm{~b} \mathrm{~A}$ & $1260 \mathrm{~b} \mathrm{~A}$ & $1038 b \mathrm{~A}$ & 857d A \\
\hline Hooter & $45,4 a B$ & $54,3 a \mathrm{~A}$ & $50,4 a A$ & $50,0 \mathrm{a} A$ & $1402 \mathrm{~b} \mathrm{~A}$ & $682 d B$ & 639 c B & $1692 \mathrm{~b} \mathrm{~A}$ \\
\hline BRS Radiante & $33,3 \mathrm{~d} \mathrm{~B}$ & $37,9 \mathrm{e} A$ & $40,0 \mathrm{c} \mathrm{A}$ & $36,6 \mathrm{c} \mathrm{A}$ & $1335 \mathrm{c} A$ & $1361 \mathrm{a} A$ & 1272a A & $1412 \mathrm{c} \mathrm{A}$ \\
\hline Cal 96 & $42,1 \mathrm{bB}$ & $52,8 \mathrm{a} A$ & $50,6 \mathrm{a} A$ & $53,8 \mathrm{a} A$ & $1188 \mathrm{c} A B$ & $1568 \mathrm{a} A$ & $676 c \mathrm{~B}$ & $1788 \mathrm{~b} \mathrm{~A}$ \\
\hline Branco Graúdo & $33,2 \mathrm{~dB}$ & $46,4 \mathrm{c} \mathrm{A}$ & $44,0 \mathrm{~b} \mathrm{~A}$ & $46,4 \mathrm{~b} \mathrm{~A}$ & $1032 d A B$ & $1475 a \mathrm{AB}$ & $989 b \mathrm{~B}$ & $1662 \mathrm{~b} \mathrm{~A}$ \\
\hline WAF 75 & $34,5 \mathrm{~d} C$ & $55,6 \mathrm{a} A$ & $43,6 \mathrm{~b} B$ & $54,6 \mathrm{a} A$ & 775d AB & 557d B & $576 c \mathrm{~B}$ & $1342 \mathrm{c} \mathrm{A}$ \\
\hline IAC Galante & & $28,1 \mathrm{~g} \mathrm{~A}$ & $24,7 \mathrm{e} A$ & $28,9 \mathrm{~d} A$ & & $1717 a A$ & $1267 a A$ & $1747 \mathrm{~b} \mathrm{~A}$ \\
\hline IAC Centauro & & $26,0 \mathrm{~g} \mathrm{~A}$ & $23,6 \mathrm{e} A$ & $25,3 d A$ & & 1570a A & $915 b B$ & $2115 a \mathrm{~A}$ \\
\hline Xamego & & $20,8 \mathrm{~h} \mathrm{~A}$ & $22,5 \mathrm{e} A$ & $24,5 \mathrm{~d} A$ & & $1384 a \mathrm{~A}$ & $1613 a A$ & 2004a A \\
\hline BRS MG Realce & & $34,8 f \mathrm{~A}$ & $37,9 \mathrm{c} \mathrm{A}$ & $36,8 \mathrm{c} \mathrm{A}$ & & $1380 \mathrm{a} A$ & $1464 a A$ & $1602 \mathrm{~b} \mathrm{~A}$ \\
\hline Rosinha G2 & & $23,3 \mathrm{~h} \mathrm{~A}$ & $25,1 \mathrm{e} A$ & $22,2 \mathrm{~d} \mathrm{~A}$ & & $1367 a B$ & $1547 a B$ & 2316a A \\
\hline Vermelho Graúdo & & $48,5 \mathrm{~b} \mathrm{~A}$ & $37,0 \mathrm{c} \mathrm{B}$ & $41,3 b \mathrm{~B}$ & & 1333a A & $188 \mathrm{~d} \mathrm{~B}$ & 371 e B \\
\hline Iraí & & $36,9 \mathrm{e} A$ & $37,2 \mathrm{c} \mathrm{A}$ & $36,0 \mathrm{c} \mathrm{A}$ & & $1222 \mathrm{~b} \mathrm{~A}$ & $1258 \mathrm{a} A$ & $1788 \mathrm{~b} \mathrm{~A}$ \\
\hline IAC Harmonia & & $42,3 \mathrm{~d} A$ & $40,2 \mathrm{c} \mathrm{A}$ & $39,9 \mathrm{~b} \mathrm{~A}$ & & $1216 b \mathrm{~A}$ & $1084 \mathrm{~b} \mathrm{~A}$ & $1654 \mathrm{~b} \mathrm{~A}$ \\
\hline Dark Red Kidney & & $45,7 \mathrm{c} \mathrm{A}$ & $47,8 \mathrm{a} A$ & $43,7 \mathrm{~b} \mathrm{~A}$ & & $1132 b \mathrm{AB}$ & $386 \mathrm{~d} C$ & $1757 \mathrm{~b} \mathrm{~A}$ \\
\hline IAC Jabola & & $40,5 \mathrm{~d} A$ & $31,6 \mathrm{~d} B$ & $40,4 \mathrm{~b} \mathrm{~A}$ & & $1039 b A B$ & $525 \mathrm{c} \mathrm{B}$ & $1236 \mathrm{c} \mathrm{A}$ \\
\hline Cranberry & & $45,2 \mathrm{c} \mathrm{A}$ & $48,0 \mathrm{a} A$ & $43,2 \mathrm{~b} \mathrm{~A}$ & & $966 \mathrm{c} \mathrm{A}$ & $1284 a \mathrm{~A}$ & $1401 \mathrm{c} \mathrm{A}$ \\
\hline OTG 07-09 & & $49,9 \mathrm{~b} \mathrm{~A}$ & $47,3 \mathrm{a} A$ & $46,1 \mathrm{~b} \mathrm{~A}$ & & $953 \mathrm{c} \mathrm{A}$ & $765 \mathrm{c} A$ & $1247 \mathrm{c} \mathrm{A}$ \\
\hline TВ 02-24 & & $31,9 f A$ & $30,0 \mathrm{~d} A$ & $33,2 \mathrm{c} \mathrm{A}$ & & $916 c$ B & $1301 a B$ & 1978a A \\
\hline IAC Boreal & & $54,4 \mathrm{a} A$ & $38,2 \mathrm{C} \mathrm{C}$ & $50,0 a A B$ & & 899 c BC & $263 d C$ & 2171a A \\
\hline 38 MOM p5-13 & & $37,7 \mathrm{e} A$ & $37,0 \mathrm{c} \mathrm{A}$ & $36,3 \mathrm{c} A$ & & 769 c B & 1389a AB & $2015 a A$ \\
\hline IAC Esperança & & $37,2 \mathrm{e} A$ & $29,9 d B$ & $34,0 \mathrm{c} A B$ & & $726 \mathrm{~d} A$ & $267 d A$ & $622 d A$ \\
\hline OTG 07-03 & & $51,5 \mathrm{~b} \mathrm{~A}$ & $46,7 a \mathrm{AB}$ & $43,8 b \mathrm{~B}$ & & $704 d A$ & $729 \mathrm{c} \mathrm{A}$ & $1313 \mathrm{c} \mathrm{A}$ \\
\hline OTG 07-01 & & $53,7 \mathrm{aA}$ & $47,7 \mathrm{a} B$ & $46,0 \mathrm{~b} B$ & & 437d B & $910 \mathrm{bB}$ & $1675 \mathrm{~b} \mathrm{~A}$ \\
\hline Média & 39,2 & 42,7 & 39,9 & 41,6 & 1447,0 & 1075,0 & 941,0 & 1540,0 \\
\hline C.V. (\%) & 6,5 & 5,4 & 7,1 & 3,4 & 13,8 & 17,5 & 23,4 & 12,9 \\
\hline
\end{tabular}

Médias seguidas pela mesma letra minúscula na coluna não diferem entre si, pelo teste de Scott-Knott $(\mathrm{p}=0,05)$, e maiúscula na linha, pelo teste de Tukey $(p=0,05) .{ }^{1}$ Ambientes: Amb. 1: cultivo de safra de 2010/2011 em Santa Maria; Amb. 2: cultivo de safrinha em Santa Maria; Amb. 3: cultivo de safra de 2011/2012 em Santa Maria; Amb. 4: cultivo de safra de 2011/2012 em Jaguari.

Estimativa de correlação positiva e de moderada magnitude foi obtida entre a produtividade de grãos e o número de vagens por planta $(r=0,4704)$, o número de grãos por planta $(r=0,5558)$ e o número de grãos por vagem $(r=0,4254)$ (Tabela 4). Estimativas de correlação similares em magnitude e sinal foram verificadas entre os mesmos caracteres, em estudos preliminares, em avaliação de linhagens desenvolvidas pela pesquisa de grãos pretos (RIBEIRO et al., 2001b) e de cultivares crioulas de feijão (CABRAL et al., 2011). No presente estudo, a seleção para o aumento do número de vagens por planta, do número de grãos por planta e do número de grãos por vagem será de eficiência moderada para aumentar a produtividade de grãos, devido à magnitude das estimativas de correlações obtidas.
A massa de 100 grãos apresentou correlação negativa e de moderada magnitude com 0 número de grãos por planta $(r=-0,6366)$ e com o número de grãos por vagem ( $r=-0,6877)$; portanto, o aumento do número de grãos por planta e do número de grãos por vagem implicará em redução da massa de 100 grãos. Nienhuis \& Sing (1986), também, constataram correlação negativa entre a massa de 100 grãos e o número de grãos por vagem em feijão. De acordo com os autores, o efeito de compensação entre os componentes da produtividade de grãos pode limitar o sucesso da seleção indireta para o desenvolvimento de linhagens de feijão com grãos de tamanho grande e de alta produtividade de grãos.

O diagnóstico de multicolinearidade revelou a presença de colinearidade moderada a forte, com número de condição igual a 214,15. 
Como o número de grãos por planta apresentou alto coeficiente de variação $(37,30 \%)$ (Tabela 1$)$ e alta correlação com o número de vagens por planta $(r=0,8171)$ e com o número de grãos por vagem $(r=0,7390)$ (Tabela 4), optou-se por descartar esse caráter. Com a retirada do número de grãos por planta, o número de condição passou a 8,89 , permitindo a realização da análise de trilha sem colinearidade.

$\mathrm{Na}$ análise de trilha, constatou-se que o número de vagens por planta e o número de grãos por vagem apresentaram os maiores efeitos diretos positivos sobre a produtividade de grãos $(0,4209$ e 0,4241 , respectivamente $)$ (Tabela 5), com coeficiente de correlação similar em magnitude e sinal $(r=0,4704$ e $r=0,4254$, respectivamente) (Tabela 4). Neste caso, as correlações explicam a verdadeira associação existente (VENCOVSKI \& BARRIGA, 1992), e a seleção direta para obter maior número de va- gens por planta e maior número de grãos por vagem poderá ser utilizada para a seleção de linhagens de feijão de grãos especiais com maior produtividade de grãos.

Resultados distintos sobre as relações de causa e de efeito dos componentes da produtividade de grãos em feijão foram observados em diferentes anos de cultivo (RIBEIRO et al., 2003) e locais de avaliação (BARILI et al., 2011; ZILIO et al., 2011). Nesse caso, para cada ambiente, haverá um caráter com maior efeito direto sobre a produtividade de grãos, como observado por Zilio et al. (2011). Isso dificulta a seleção indireta. No presente estudo, a análise de trilha foi executada com dados médios de quatro ambientes, ou seja, envolveu dados obtidos em anos, épocas e locais diferentes. Do ponto de vista prático, as informações obtidas em quatro ambientes apresentam maior confiabilidade do que estimativas obtidas em um único ambiente.

Tabela 4 - Estimativas de coeficientes de correlação de Pearson para os caracteres produtividade de grãos (PROD), número de vagens por planta (NVP), número de grãos por planta (NGP), número de grãos por vagem (NGV) e massa de 100 grãos (M100G) de linhagens de feijão de grãos especiais obtidas em quatro ambientes.

\begin{tabular}{ccccc}
\hline Caracteres & NVP & NGP & NGV & M100G \\
\hline PROD & $0,4704^{*}$ & $0,5558^{*}$ & $0,4254^{*}$ & $-0,2982$ \\
NVP & & $0,8171^{*}$ & 0,2497 & $-0,3739^{*}$ \\
NGP & & & $0,7390^{*}$ & $-0,6366^{*}$ \\
NGV & & & & $-0,6877^{*}$ \\
\hline
\end{tabular}

* Significativo pelo teste $t(\mathrm{p}=0,05) ; \mathrm{n}=116$ observações.

Tabela 5 - Estimativas dos coeficientes de correlação de Pearson e respectivas estimativas dos efeitos diretos e indiretos do número de vagens por planta (NVP), número de grãos por vagem (NGV) e massa de 100 grãos (M100G) sobre a produtividade de grãos (PROD) de linhagens de feijão de grãos especiais, obtidas em quatro ambientes.

\begin{tabular}{lrrr}
\hline \multicolumn{1}{c}{ Efeito } & NVP & NGV & M100G \\
\hline Direto sobre PROD & 0,4209 & 0,4241 & 0,1508 \\
Indireto via NVP & - & 0,1051 & $-0,1574$ \\
Indireto via NGV & 0,1059 & - & $-0,2916$ \\
Indireto via M100G & $-0,0564$ & $-0,1037$ & - \\
Total (Pearson) & $0,4704^{*}$ & $0,4254^{*}$ & $-0,2982$ \\
Coeficiente de determinação $=0,33$ & & & \\
\hline${ }^{*}$ Significativo pelo teste $t(\mathrm{p}=0,05) ; \mathrm{n}=116$ observações. &
\end{tabular}

Os demais componentes da produtividade de grãos apresentaram efeitos diretos e indiretos baixos (negativos e positivos) com a produtividade de grãos. Efeitos indiretos positivos e negativos de baixa magnitude entre a produtividade de grãos e os componentes da produtividade de grãos foram previamente verificados em feijão-carioca (RIBEIRO et al., 2001a) e preto (RIBEIRO et al., 2001b).

A seleção visual pelo maior número de vagens por planta é mais fácil de ser implementada na rotina do programa de melhoramento de feijão, do que a seleção pelo maior número de grãos por vagem. Portanto, o descarte de plantas nitidamente inferiores para o caráter número de vagens por planta é recomendado no processo de seleção de linhagens de feijão de grãos especiais. Com o uso desta estratégia, pretende-se manter maior número de linhagens promissoras nas gerações segregantes e aumentar o número de linhagens selecionadas de feijão de grãos especiais com alta produtividade de grãos nas gerações avançadas. 


\section{Conclusões}

Os componentes da produtividade de grãos em feijão de grãos especiais são afetados pela interação linhagem $x$ ambiente.

As cultivares IAC Galante, Xamego, BRS MG Realce e Rosinha G2 são de alta produtividade de grãos, sendo promissoras para o cultivo nos ambientes avaliados.

A seleção indireta para o número de vagens por planta e o número de grãos por vagem é de eficiência moderada para o aumento da produtividade de grãos em linhagens de feijão de grãos especiais.

\section{Referências}

BARILI, L. D.; VALE, N. M.; MORAIS, P. P. P.; BALDISSERA, J. N. C.; ALMEIDA, C. B.; ROCHA, F.; VALENTINI, G.; BERTOLDO, J. G.; COIMBRA, J. L. M.; GUIDOLIN, A. F. Correlação fenotípica entre componentes do rendimento de grãos de feijão comum (Phaseolus vulgaris L.). Semina: Ciências Agrárias, Londrina, v.32, n.4, p.263-1274, 2011.

BLAIR, M. W.; GONZÁLEZ, L. F.; KIMANI, P. M.; BUTARE, L. Genetic diversity, inter-gene pool introgression and nutritional quality of common beans (Phaseolus vulgaris L.) from Central Africa. Theorical Applied Genetic, New York, v.121, n.2, p.237-248, 2010.

BROUGHTON, W. J.; HERNANDEZ, G.; BLAIR, M.; BEEBE, S.; GEPTS, P.; VANDERLEYDEN, J. Beans (Phaseolus spp.): model food legumes. Plant Soil, Dordrecht, v.252, p.55-128, 2003.

CABRAL, P. D. S.; SOARES, T. C. B.; LIMA, A. B. P.; SOARES, Y. J. B.; SILVA, J. A. Análise de trilha do rendimento de grãos de feijoeiro (Phaseolus vulgaris L.) e seus componentes. Revista Ciência Agronômica, Fortaleza, v.42, n.1, p.132-138, 2011

CARGNELUTTI FILHO, A.; RIBEIRO, N. D.; BURIN, C.; TOEBE, M.; CASAROTTO, G. Número necessário de experimentos para a análise de trilha em feijão. Ciência Rural, Santa Maria, v.41, n.4, p.564-572, 2011.

CONAB-Companhia Nacional de Abastecimento. Acompanhamento da safra brasileira: grãos: safra 2011/2012: oitavo levantamento. Brasília: CONAB, 2012. 36p. Disponível em: http://www.conab.gov.br/conabweb. Acesso em: 28 maio 2012

CRUZ, C. D. Programa genes: estatística experimental e matrizes. Viçosa: UFV, 2006. 382p.
CRUZ, C. D.; CARNEIRO, P. C. S. Modelos biométricos aplicados ao melhoramento de plantas. Viçosa: UFV, 2003. 585p.

CTSBF-Comissão Técnica Sul Brasileira de Feijão. Informações técnicas para o cultivo de feijão na Região Sul brasileira 2009. Florianópolis: EPAGRI, 2010. 164p.

FARIA, A. P.; MODA-CIRINO, V.; BURATTO, J. S.; SILVA, C. F. B.; DESTRO, D. Interação genótipo $x$ ambiente na produtividade de grãos de linhagens e cultivares de feijão. Acta Scientiarum Agronomy, Maringá, v.31, n.4, p.579-585, 2009.

FURTADO, M. R.; CRUZ, C. D.; CARDOSO, A. A.; COELHO, A. D. F.; PETERNELLI, L. A. Análise de trilha do rendimento do feijoeiro e seus componentes primários em monocultivo e em consórcio com a cultura do milho. Ciência Rural, Santa Maria, v.32, n.2, p.217-220, 2002.

GONÇALVES, S. L.; WREGE, M. S.; CARAMORI, P. H.; MARIOT, E. J.; ABUCARUB NETO, M. Probabilidade de ocorrência de temperaturas superiores a $30^{\circ} \mathrm{C}$ no florescimento do feijoeiro (Phaseolus vulgaris $\mathrm{L}$ ), cultivado na safra das águas no Estado do Paraná. Revista Brasileira de Agrometeorologia, Santa Maria, v.5, n.1, p.99-107, 1997.

GONÇALVES, J. G. R.; CHIORATO, A. F.; MORAIS, L. K.; PERINA, E. F.; FARIAS, F. L.; CARBONELL, S. A. M. Estudo da estabilidade fenotípica de feijoeiro com grãos especiais. Ciência e Agrotecnologia, Lavras, v.34, n.4, p.922-931, 2010.

KUREK, A. J.; CARVALHO, F. I. F.; ASSMANN, I. C.; MARCHIORO, V. S.; CRUZ, P. J. Análise de trilha como critério de seleção indireta para rendimento de grãos em feijão. Revista Brasileira de Agrociência, Pelotas, v.7, n.1, p.29-32, 2001.

MAPA-Ministério da Agricultura, Pecuária e Abastecimento. Zoneamento agrícola de risco climático: cultivares de feijão - ano - safra 2011/2012. Brasília: MAPA, 2012. Disponível em: <http://www.agricultura.gov.br/politicaagricola/zoneamento-agricola/portariassegmentadas-por-uf>. Acesso em: 30 jul. 2012.

MELO, L. C.; MELO, P. G. S.; FARIA, L. C.; DIAZ, J. L. C.; PELOSO, M. J. D.; RAVA, C. A.; COSTA, J. G. C. Interação com ambientes e estabilidade de genótipos de feijoeiro-comum na Região Centro-Sul do Brasil. Pesquisa Agropecuária Brasileira, Brasília, v.42, n.5, p.715-723, 2007. 
NIENHUIS, J.; SINGH, S. P. Combining ability analyses and relationships among yield, yield components, and architectural traits in dry bean. Crop Science, Madison, v.26, n.1, p.21-27, 1986.

PIANA, C. F. B.; ANTUNES, I. F.; SILVA, J. G. C.; SILVEIRA, E. P. Adaptabilidade e estabilidade do rendimento de grãos de genótipos de feijão. Pesquisa Agropecuária Brasileira, Brasília, v.34, n.4, p.553-564, 1999.

RIBEIRO, N. D.; MELLO, R. M.; DALLA COSTA, R.; SLUSZZ, T. Correlações genéticas de caracteres agromorfológicos e suas implicações na seleção de genótipos de feijão carioca. Revista Brasileira de Agrociência, Pelotas, v.7, n.2, p.93-99, 2001a.

RIBEIRO, N. D.; STORCK, L.; MELLO, R. M. Correlações genéticas de caracteres agromorfológicos e suas implicações na seleção de genótipos de feijão preto. Revista Científica Rural, Bagé, v.6, n.1, p.168-176, 2001b.

RIBEIRO, N. D.; HOFFMANN JÚNIOR, L.; STROSCHEIN, M. R.; POSSEBON, S. B. Genotype $x$ environment interaction in common bean yield and yield components. Crop Breeding and Applied Biotechnology, Viçosa, v.3, n.1, p.27-34, 2003.

STEEL, R. G. D.; TORRIE, J. H.; DICKEY, D. A. Principles and procedures of statistics: a biometrical approach. $3^{\text {ed }}$. New York: McGraw Hill Book, 1997. 666p.
TALUKDER, Z. I.; ANDERSON, E.; MIKLAS, P. N.; BLAIR, M. W.; OSORNO, J.; DILAWARI, M.; HOSSAIN, K. G. Genetic diversity and selection of genotypes to enhance $\mathrm{Zn}$ and Fe content in common bean. Canadian Journal of Plant Science, Ottawa, v.90, n.1, p.49-60., 2010.

THUNG, M.; SOARES, D. M.; AIDAR, H. Agregação de valores com feijões especiais. In: KLUTHCOUSKI, J.; STONE, L. F.; AIDAR, H. Fundamentos para uma agricultura sustentável, com ênfase na cultura do feijoeiro. Santo Antônio de Goiás: Embrapa Arroz e Feijão, 2009. p.83-96.

VENCOVSKY, R.; BARRIGA, P. Genética biométrica no fitomelhoramento. Ribeirão Preto: Revista Brasileira de Genética, 1992. 496p.

ZILIO, M.; COELHO, C. M. M.; SOUZA, C. A.; SANTOS, J. C. P.; MIQUELLUTI, D. J. Contribuição dos componentes de rendimento na produtividade de genótipos crioulos de feijão (Phaseolus vulgaris

L.). Revista Ciência Agronômica, Fortaleza, v.42, n.2, p.429-438, 2011.

ZIMMERMANN, M. J. O.; TEIXEIRA, M. G. Origem e evolução. In: ARAÚJO, R. S.; RAVA, C. A.; STONE, L. F.; ZIMMERMANN, M. J. O. Cultura do feijoeiro comum no Brasil. Piracicaba: Potafós, 1996. p.57-70. 